\title{
Supportive Interactions, Negative Interactions, and Depressed Mood $^{1}$
}

\author{
Tonya L. Schuster ${ }^{2}$ \\ The University of Southern California
}

Ronald C. Kessler ${ }^{2}$ and Robert H. Aseltine, Jr.

The University of Michigan

Research on the association between social relationships and emotional functioning has emphasized the health-promoting effects of social support. Yet there is reason to believe that the absence of negative social interactions may be more important for mental health than the presence of supportive interactions. In this investigation we clarify important characteristics concerning the source, the recipient, and the combined influence of support and negativity. Data are presented regarding supportive and negative interactions with spouse, relatives, and friends; regression analyses suggest that negative interactions are more predictive of depressed mood than supportive interactions (specifically with spouse and friends). We also document several specifications suggesting directions for future research on the special importance of interactions in intimate relationships and the synergistic effects of situations in which supportive and negative interactions both occur.

Although it has long been known that personal relationships can be the source of both great comfort and great frustration, research on social support over

\footnotetext{
${ }^{1}$ This research was sponsored by Grant T32 MH168006, by Research Scientist Development Award $1 \mathrm{~K} 02 \mathrm{MH} 00507$, and by MERIT Award 1 M01 MH16806 from the National Institute of Mental Health. We thank Jean Converse, Jane McLeod, Stanley Presser, Elaine Wethington, and the students of the Detroit Area Study for their assistance in collecting the data. Niall Bolger, Jane McLeod, Elaine Wethington, Camille Wortman, and anonymous reviewers provided helpful comments on an earlier draft.

${ }^{2}$ All correspondence should be sent to Tonya L. Schuster, University of Southern California, Los Angeles, Callifornia 90089-0191, or Ronald C. Kessler, Institute for Social Research, University of Michigan, Ann Arbor, Michigan 48106-1248.
} 
the past decade has emphasized the supportive aspects of social ties and neglected the negative aspects. But as research on social support aims increasingly to develop interventions, it becomes increasingly important to understand the full range of ways in which social relationships can affect health and wellbeing (Coyne \& DeLongis, 1986; Gottlieb, 1985). As shown in recent research, support attempts often fail to such a degree that they actually increase the stress of people they are intended to help (Wortman \& Lechmann, 1985). Putatively supportive social relationships, furthermore, often have elements that create stressful obligations for reciprocity or that expose people to disappointments, conflicts, tensions, and unpleasantness (Fiore, Becker, \& Coppel, 1983; Pagel, Erdly, \& Becker, 1987; Rook, 1984; Sandler \& Barrera, 1984; Shinn, Lechmann, \& Wong, 1984). It is this latter form of negativity that we address by studying the joint effects of supportive and negative social interactions. ${ }^{3}$

Our understanding of the effects of negativity in social relationships is limited, and the literature aimed at studying the influence of supportive and negative interactions together is fairly new. We contribute to this growing literature by presenting data on the distributions and effects of supportive and negative interactions in a large community sample of married couples. The analyses separately consider interactions with spouse, relatives, and friends in order to distinguish the prevalence and influence of support and negativity from these three typical sources. We also examine gender differences in exposure and reactivity to supportive and negative interactions. Further, since it seems reasonable to assume that most social relationships are neither exclusively supportive nor exclusively negative, we examine synergistic effects of supportive and negative interactions.

\section{PREVIOUS RESEARCH}

In the relatively few investigations that have considered the influence of both support and negativity at the same time, results suggest that the correlation between supportive and negative interactions is weak. This means that support and negativity both occur in most relationships (O'Brien, Wortman,

\footnotetext{
${ }^{3}$ We have not attempted to address all literatures dealing with various forms of negativity in relationships; rather we are specifically dealing with social ties that seemingly entail both supportive and negative aspects or influences at the same time. With this specific focus, nevertheless, conceptualizations of negativity (negative support, negative interactions) are inconsistent and quite varied. Our conceptualization broadly follows those referenced above, particularly the domains initiated in the research of Rook (1984) on negative interaction (conflict, tensions, demands). (See also reviews in Jung, 1987; Rook \& Pietromonaco, 1987; and Shinn et al., 1984.)
} 
\& Joseph, 1986; Ruehlman \& Wolchik, 1988). Research in this area has typically found that negative interactions occur less frequently than supportive interactions, and that negativity is more important than support in predicting emotional functioning (Barrera, 1981; Fiore et al., 1983; Henderson, Byrne, Duncan-Jones, Scott, \& Adcock, 1980; Henderson, Byrne et al., 1978; Henderson, Duncan-Jones, McAuley, \& Ritchie, 1978; Lehmann, Shinn, Allen, \& Simko, 1983; Rook, 1984; Sandler \& Barrera, 1984; Stephens, Kinney, Ritchie, \& Norris). ${ }^{4}$ Whether or not these general findings apply across all sources of support and negativity is unknown, and a number of potentially important specifications have not yet been addressed.

Previous research in the social support literature has shown that support from some sources is more beneficial than from others (Denoff, 1982; Dunkel-Schetter, 1984; Kobasa \& Puccetti, 1983; LaRocco, House, \& French, 1980; Wood \& Robertson, 1978), and there is evidence that the influence of negativity may also be source-specific (Shinn et al., 1984). However, only one previous study clearly differentiated the sources of both supportive and negative interactions (Abbey, Abramis, \& Caplan, 1985). Separately measuring social support and social conflict with people in general, some one person, and the person closest to you, Abbey et al. found source specificity for both supportive and negative aspects of social relationships in a sample of university students. In the present investigation, the data allow us to separately consider interactions with spouse, family, and friends.

In the same way that there may be source specificity with regard to the effect of supportive and negative interactions, there may also be distinctions with regard to characteristics of the recipient. Although the literature on gender differences in the receipt of overall support is equivocal (see Rosario, Shinn, Morch, \& Huckabee, 1988), Wong (1985/1986) found that women reported more support from friends and relatives whereas men reported more support from their spouses. Further, various studies have suggested that marriage is more beneficial to health for men, whereas women benefit as much or more than men from relationships with relatives and friends (see House, Landis, \& Umberson, 1988). In the only previous study we could find that

\footnotetext{
${ }^{4}$ As noted by Shinn et al. (1984, p. 64), the low correlation between positive and negative interactions provides an interesting parallel to the finding of Bradburn and Caplovitz (1965) concerning the independence of positive and negative affect. The research on subjective well-being has further shown that positive events influence positive affect, negative events influence negative affect, and that global well-being is a balance of these dimensions (see Diener, 1984). In addition, although outcome variables differ from those in this study, the literature on intimate relationships also suggests that positivity (satisfactions) and negativity (tensions) have independent contributions to marriage happiness (Orden \& Bradburn, 1968), that displeasurable behaviors account for more variance in marital satisfaction than pleasurable behaviors (Wills, Weiss, \& Patterson, 1974), and that stressors have a larger effect than social support on the quality of family life (Pittman \& Lloyd, 1988).
} 
examined gender differences with negative interaction effects, Henderson et al. (1980) found weaker associations for men than women in predicting neurosis in a general population sample. In the present report we focus on gender differences in exposure and reactivity to both supportive and negative interactions, again separately considering spouse, relatives, and friends.

Virtually all research that has considered the joint influence of both support and negativity in social relationships has implicity assumed that the effects are additive, that is, that the effect of supportive interaction on emotional functioning does not depend on the amount of negative interaction in a person's social network. ${ }^{5}$ In the few previous investigations that have searched for nonadditivity of this sort, the evidence has been mixed. Rook (1984) failed to find a significant interaction between supportive and negative aspects of social network relationships in a sample of elderly widowed women. However, with samples of university students, Abbey et al. (1985) found evidence that for one type of relationship (some one person) support buffered the effects of social conflict on well-being, and Sandler and Barrera (1984) obtained a significant positive interaction between conflicted network size (number of persons who were both a source of supportive and of upsetting interactions) and stress in predicting psychological distress. Finally, Pagel et al. (1987) observed that upsetting interactions with network members had more adverse consequences among spouses of Alzheimer's patients whose networks were generally supportive than among those whose networks were generally unsupportive. In the present study, we investigate whether similar interactions can be found in a broader segment of the general population.

\section{METHODS}

\section{Sample}

The data used here were obtained in a community survey administered in 1985 by the staff of the Detroit Area Study and the Survey Research Center at the University of Michigan. The sample was based on an equal-probability

\footnotetext{
${ }^{5}$ Negative interactions make up a prominent class of interpersonal stressful events (Shinn et al., 1984, pp. 62-64). It may be argued, therefore, that this issue has been addressed indirectly in the literature on the stress-buffering effects of social support. Although a few studies have disaggregated measures of life events (Eckenrode \& Gore, 1981; Kessler \& McLeod, 1984; Pearlin, Lieberman, Menaghan, \& Mullan, 1981), tests of the buffering hypothesis for this particular class of stressful events have not been reported. Further evidence may be taken from the life events literature which has found significant buffering effects of positive events on the pathogenic effects of high levels of stress as measured by number of negative events (e.g., Cohen \& Hoberman, 1983).
} 
two-stage cluster design including nonblack married couples aged 18 through 65 residing in noninstitutionalized housing in the Detroit Metropolitan Area. ${ }^{6}$ A total of 1,755 respondents ( 820 male, 935 female) were interviewed faceto-face, representing $76 \%$ of eligible respondents. The interview averaged 78 minutes and covered a broad range of topics related to roles and rolerelated stress, life events, social support, personality, coping, and mental health. Demographic characteristics of the sample closely refleted those of the target population. Mean age of respondents was 42 years, mean education was 13 years, and mean income (from 1984) was close to $\$ 42,000$. Consistent with these characteristics, the majority of men (83.9\%) were employed full-time and a large proportion ( $48 \%$ ) of women were employed at least 20 hours a week.

\section{Measures}

The available measures of interest from the broader survey included six separate indices of supportive and negative social interaction with spouse, friends, and relatives. Supportive spouse interaction was indicated by responses to questions about (a) how much your spouse understands the way you feel about things, (b) how much you can depend on your spouse to be there when you really need them, (c) how much your spouse shows concern for your feelings and problems, (d) how much you can trust your spouse to keep their promises to you, and (e) how much you can open up to your spouse about things that are really important to you. The alpha reliability of the five-item index was .84, and was derived from previous measures of affective support (Turner, Frankel, \& Levin, 1983). Negative spouse interaction was indicated by responses to questions about (a) how much tension there is between you and your spouse, (b) how often you have an unpleasant disagreement with your spouse, (c) how often things become tense when the two of you disagree, (d) how often your spouse says cruel or angry things during a disagreement, and (e) how often the two of you both refuse to compromise during disagreements. The alpha reliability of this five-item index was .76.

Interactions with friends and relatives were measured with parallel items. Supportive interactions were indicated by responses to two commonly used

\footnotetext{
${ }^{6}$ Census data showed that only a small percentage of the people residing in the central city of Detroit would be eligible for the study, so the target population was limited to residents of the metropolitan area excluding those in the central city. This redefinition of the area eligible for the survey allowed us to retain a multistage equal probability sample representative of over $95 \%$ of the nonblack married couples in the metropolitan are while reducing considerably the magnitude of the screening effort. For more detailed information on methodology, as well as other findings from these data, see Mattlin, Wethington, and Kessler (in press).
} 
questions in the domain of affective support about (a) how often friends (or relatives) make you feel cared and (b) how often they express interest in how you are doing. Alpha reliabilities of this two-item index were .64 (friends) and .75 (relatives). Negative interactions were indicated by responses to questions about (a) how often friends (or relatives) make too many demands on you, (b) how often they criticize you, and (c) how often they create tensions or arguments with you. The alpha reliabilities of this three-item index were .56 (friends) and .74 (relatives). (The alpha coefficients for these indices are lower than accepted levels, and accordingly warrant caution in interpreting results. The low reliabilities are thought to derive, in part, from the heterogeneous content of the items.)

All the social interaction indices were scaled so that the theoretically lowest scores (i.e., those in which a respondent gave the lowest possible response to all items) were coded 0 and the theoretically highest scores were coded $1 .{ }^{7}$ Despite the common scaling of all indices, caution should be noted concerning dissimilarities in the actual items. Differences between the spouse interaction items and those for relatives/friends, and differences in the domains of the support and negativity indices, preclude rigorous comparisons of means across these categories. However, the relative prevalences of supportive and negative interactions can be compared across relatives versus friends and for male versus female.

In line with a great deal of research on social support effects, the outcome variable was measured with items from the depression scale of the revised Hopkins Symptom Checklist (Derogatis, 1977). This scale contains 10 items rated on a 4-point scale of "How often did you experience feelings like these during the past 30 days?" The scale was scored by standardizing each item to a mean of 0 and variances of 1 , summing across all the items, and then standardizing the total. High scores indicate more distress. The alpha reliability of this 10 -item index was $.84 .^{8}$

\section{RESULTS}

\section{Prevalence and Association of Supportive and Negative Interactions}

Means and standard deviations of the supportive and negative interaction scales are reported separately for male and female respondents in Table

TThe rescaling involved simple linear transformations. All separate items were measured in 4-point Likert scales. The indices were created by summing the item scores to yield composites with theoretical ranges between $i$ (number of items) and $4 \mathrm{i}$. The transformation was of the form $I_{t}=(I-i) /(4 i-4)$, where $I$ is the index in its original metric and $I_{t}$ is the transformed index.

${ }^{8}$ All analyses reported in this paper were also carried out for the anxiety scale of the revised Hopkins Symptom Checklist (alpha reliability $=.83$ ). These results are not reported here because they were virtually identical to those involving the depression scale. Anxiety and depression are correlated .66 in this sample. 
Table I. Means of Supportive and Negative Interaction with Spouse, Relatives, and Friends ${ }^{\alpha}$

\begin{tabular}{|c|c|c|c|c|c|c|}
\hline \multirow[b]{2}{*}{ Scale } & \multicolumn{2}{|c|}{ Total sample $(N=1,752)$} & \multicolumn{2}{|c|}{ Male $(n=817)$} & \multicolumn{2}{|c|}{ Female $(n=936)$} \\
\hline & $M$ & $S D$ & $M$ & $\overline{S D}$ & $M$ & $S D$ \\
\hline Spouse supportive & .880 & .161 & .911 & .127 & .852 & .182 \\
\hline Spouse negative & .338 & .171 & .341 & .165 & .335 & .177 \\
\hline Relative supportive & .874 & .188 & .846 & .196 & .897 & .177 \\
\hline Relative negative & .436 & .223 & .413 & .207 & .456 & .233 \\
\hline Friend supportive & .861 & .177 & .813 & .190 & .902 & .152 \\
\hline Friend negative & .377 & .170 & .388 & .172 & .367 & .168 \\
\hline
\end{tabular}

${ }^{a}$ Comparisons were significant at the .01 level for the following: Male versus female-spouse, friend, relative supportive; friend, relative negative. Friend versus relative-supportive for male; negative for male, female.

I. It is not possible to compare the relative magnitudes of the support scores with those of the negative interaction scores in a rigorous way because the two types of measures are based on nonparallel items. It is clear, nonetheless, that the means of all support scales are skewed toward the upper limit of the range (with none having a mean less than 0.80 on scales with theoretical maxima of 1.0), while all the negative interaction scales have means skewed toward the lower limit of the range (with none having a mean greater than 0.44 on scales with theoretical minima of 0.0 ). This same general pattern has been observed in previous studies (Rook, 1984; Stephens et al., 1987).

In some ways this result is not surprising because we would expect relationships characterized by more negative interactions to be terminated or minimized. With this thought in mind, it is interesting to note that the absolute levels of negative interaction, as well as the ratio of negative to supportive interactions, were significantly higher $(t$ statistic) for relatives $(0.44: 0.87)$ than for friends $(0.38: 0.86)$. This was true for both men and women, suggesting that there is a general tendency for negative interactions to occur more often in relationships that are not based on mutual attraction in the way that friendships are determined.

Several sex differences are noteworthy. Men reported more supportive interactions with their wives (0.91) than women did with their husbands $(0.85)$. This result is broadly consistent with evidence from the literature on marital satisfaction, which found that males report better relationships with their wives than women do with their husbands (Veroff, Douvan, \& Kulka, 1981), and emphasized different types of supportive behaviors (Weiss, 1974). Women, on the other hand, reported more supportive interactions than men with their friends ( 0.90 for women and 0.81 for men). Finally, women reported more interaction than men - both supportive and negative - with their relatives. This result is consistent with evidence that women are more involved than men in maintaining kin networks (Kessler, McLeod, \& Wethington, 1985). Despite these variations across relationships and by sex of respondent, 
Table II. Correlations of Supportive and Negative Interaction with Spouse, Relatives, and Friends, and Depressed Mood, Separately for Male and Female ${ }^{a}$

\begin{tabular}{lrrrrrrr}
\hline & 1 & 2 & \multicolumn{1}{c}{3} & \multicolumn{1}{c}{4} & \multicolumn{1}{c}{5} & \multicolumn{1}{c}{6} & \multicolumn{1}{c}{7} \\
\hline 1. Depression & - & -.35 & .39 & -.18 & .18 & -.15 & .19 \\
2. Spouse supportive & -.20 & - & -.64 & .17 & -.07 & .16 & -.09 \\
3. Spouse negative & .32 & -.53 & - & -.16 & .13 & -.10 & .15 \\
4. Relative supportive & -.06 & .11 & -.11 & - & -.25 & .27 & -.06 \\
5. Relative negative & .11 & -.07 & .19 & -.01 & - & -.08 & .38 \\
6. Friend supportive & -.07 & .18 & -.18 & .19 & .01 & - & -.01 \\
7. Friend negative & .14 & -.11 & .21 & -.09 & .37 & .03 & - \\
\hline
\end{tabular}

${ }^{a}$ Lower left $=$ correlations for males; upper right $=$ correlations for females. Correlations of .04 or greater are significant at the .05 level.

the dominant pattern in these data was that supportive interactions occur much more frequently than negative interactions for both men and women across all relationships.

Linear correlations were computed for all pairs of the supportive and negative interaction variables in order to examine the association between support and negativity in relationships. The results of these calculations are reported in Table II. Consistent with prior evidence, weak correlations exist between supportive and negative interactions with friends (.03 among men and -.01 among women), and with relatives among men $(-.01)$. However, a moderately strong relationship exists between supportive and negative interactions with relatives among women $(-.25)$ and substantial correlations exist between supportive and negative interactions with spouse ( -.53 among men and -.64 among women). The latter result is consistent with evidence reported by Abbey et al. (1985), who found a significant negative correlation between amount of social support and amount of social conflict received from only "the person closest to you" in a sample of university students. The strong negative correlations for spouse interactions ( -.53 for male and -.54 for female) suggested that a particular individual is unlikely to be the source of both high supportive and high negative interactions. The absence of a significant correlation for friend interactions indicated that networks containing friends who are demanding, argumentative, and in other ways negative in their interactions, are no more or less likely to contain supportive friends. It is not clear why the correlation for relative interactions should be so much larger among women $(-.25)$ than men $(-.01)$. It is conceivable that interaction patterns with one particular relative influence patterns with other relatives due to the high density of kin networks, and that this reverberation occurs largely among women rather than men because women are more involved in relationships with relatives. More direct research on this 
Table III. Regression of Depression on Supportive and Negative Interaction with Spouse, Relatives, and Friends, Separately for Male and Female

\begin{tabular}{|c|c|c|c|c|}
\hline \multirow[b]{2}{*}{ Scale } & \multicolumn{2}{|c|}{ Male } & \multicolumn{2}{|c|}{ Female } \\
\hline & $b$ & $\beta$ & $b$ & $\beta$ \\
\hline Spouse supportive & -0.32 & -.04 & $-0.83^{\alpha}$ & -.15 \\
\hline Spouse negative & $1.46^{a}$ & .26 & $1.39^{a}$ & .24 \\
\hline Relative supportive & -0.10 & -.02 & $-0.46^{a}$ & -.08 \\
\hline Relative negative & 0.13 & .03 & $0.40^{a}$ & .09 \\
\hline Friend supportive & -0.08 & -.02 & -0.31 & -.05 \\
\hline Friend negative & $0.46^{a}$ & .09 & $0.54^{a}$ & .09 \\
\hline Constant & -.39 & & & \\
\hline$R^{2}$ & .11 & & & 9 \\
\hline$n$ & 781 & & & \\
\hline$F$-ratio for equation & 16.03 & & & \\
\hline
\end{tabular}

${ }^{a}$ Coefficient significant at the .05 level, two-tailed test.

issue is required before this possibility can be considered more than simple speculation. ${ }^{9}$

Correlations across sources for support and for negativity were quite variable. Most notably, frequency of negative interactions with relatives and with friends were strongly correlated among both men (.37) and women (.38), which implies that there may be general tendencies to experience or report negativity. This pattern, however, was much weaker when comparing negative spouse interactions with other sources, which suggests that the parallel questions for relatives and friends may be involved.

\section{The Effects of Interaction on Psychological Distress}

Multiple regression equations documenting the associations between social interactions and depressed mood are presented in Table III separately for men and women. The results are broadly consistent with previous ana-

\footnotetext{
${ }^{9}$ The obvious difficulty in making inferences about this issue from the data available here is that respondents, when asked to assess interactions with categories of people, such as relatives or friends, are implicitly required to average the various interpersonal relationships that are part of each category. Previous reviews have noted that this approach to measurement makes it impossible to know the reference person or persons for any particular response, nor to know whether networks described as containing both supportive and negative components are made up of individuals who are both supportive and negative or of different individuals who are either exclusively supportive or exclusively negative (Hirsch, 1981; Wortman \& Dunkel-Schetter, 1987).
} 
Table IV. Regression of Depression on Supportive and Negative Interaction with Spouse, Relatives, and Friends - Buffering Effects Separately for Male and Female ${ }^{a}$

\begin{tabular}{|c|c|c|c|c|}
\hline \multirow[b]{2}{*}{ Scale } & \multicolumn{2}{|c|}{ Male $(n=781)$} & \multicolumn{2}{|c|}{ Female $(n=908)$} \\
\hline & $b$ & $\beta$ & $b$ & $\bar{\beta}$ \\
\hline \multicolumn{5}{|l|}{ Spouse } \\
\hline Supportive $\times$ Negative & -2.36 & -.34 & 0.07 & .01 \\
\hline \multicolumn{5}{|l|}{ Relative } \\
\hline Supportive $\times$ Negative & $-1.60^{b}$ & -.34 & $-2.26^{b}$ & -.45 \\
\hline \multicolumn{5}{|l|}{ Friend } \\
\hline Supportive $\times$ Negative & -0.42 & -.07 & -1.66 & -.26 \\
\hline Constant & \multicolumn{2}{|c|}{-2.13} & \multicolumn{2}{|c|}{-1.03} \\
\hline$R^{2}$ & \multicolumn{2}{|c|}{.12} & \multicolumn{2}{|c|}{.21} \\
\hline$F$-ratio for $R^{2}$ increment over a linear model & \multicolumn{2}{|c|}{$11.6^{c}$} & \multicolumn{2}{|c|}{$25.77^{c}$} \\
\hline
\end{tabular}

${ }^{a}$ Equation includes main effects reported in Table III.

${ }^{b}$ Coefficient significant at the .05 level, one-tailed test.

${ }^{c} R^{2}$ increment significant at the .05 level.

lyses in that negative interactions are consistently associated with elevated distress, supportive interactions are consistently associated with reduced distress, and there is a trend for the associations involving negative interactions to be somewhat stronger than those involving supportive interactions (chiefly for interactions with spouse and friends). As in previous crosssectional studies of this sort, causal ambiguities regarding the influences of social interactions and depression should be noted in interpreting these results. That is, the causal ordering of low levels of support and high levels of distress, or perhaps more importantly of high levels of negativity and high levels of distress, cannot be ascertained in these data.

For women all slopes were statistically significant with the exception of support from friends, while for men only negative interactions with spouse and friends were significant. There was a trend for women to be more affected both positively and negatively than men by involvement in social relationships. For both male and female, negative interaction with spouse had by far the most pronounced effect on mental health (and/or depression may negatively affect interactions with spouse); however, for women more frequent supportive interaction with spouse was also significantly associated with lower distress. The most dramatic gender differences can be seen regarding interaction with relatives. Frequencies of both supportive and negative interactions with relatives had significant effects of similar magnitude on the mood of women whereas neither of these effects was significant among men. 


\section{Synergistic Effects of Supportive and Negative Interactions}

Our data provide an opportunity to extend previous investigations of the synergistic effects of supportive and negative interactions by separately examining spouse, relative, and friend relations individually for men and for women. The results of our analysis are presented in Table IV. The coefficients were the nonadditive effects on mood of supportive and negative interactions with spouse, friends, and relatives, controlling for the main effects of the separate component variables. ${ }^{10}$ The data show significant negative multiplicative effects of interactions with relatives among both men and women. The negative sign of both coefficients suggests that social support from relatives had a stronger effect on mood among respondents who have relationships with relatives that were characterized by high levels of negative interaction. Another way to make sense of the coefficients is to say that supportive interactions with relatives dampen the distress-producing effects of negative interactions with relatives.

\section{DISCUSSION}

The analyses presented in this report replicate and extend previous research on the joint effects of supportive and negative social interactions. Consistent with earlier reports, we find that negative interactions are as important as, or in some cases more important, than supportive interactions for depressed mood. These results argue that the absence of negative social interactions is as important as social support for emotional functioning. It is important to note that this is a sample of married persons, who are known to have higher levels of support than the nonmarried. This may attenuate the positive effects of support in these data. Nevertheless, given the consistency of this finding across studies, it is striking that support research on the relationship between social interactions and mental health has almost entirely concentrated on the health-promoting effects of social support. Our analysis argues for a redirection of this research to encompass both the supportive and negative effects of social relationships.

The analyses presented here have done little more than take a first step in this direction. We were not able to study the dimensionality of negative

\footnotetext{
${ }^{10}$ None of these interactions were reduced when polynomials of the component variables were introduced as control variables. This demonstrates that the nonadditive or multiplicative effects are not masking nonlinearities in the main effects of the component variables, which is an otherwise plausible possibility (see Kessler, 1983).
} 
social interactions but, rather, worked with a broad scheme that combined tensions, arguments, and criticisms into a single summary measure of overall exposure to negative interactions. A first step in future work must be to investigate a more exhaustive inventory and determine whether a multidimensional conception of negative social interactions improves our understanding of their effects.

It would also be useful to follow the current social support literature in thinking broadly about the negative functions of close relationships in much the same way that positive or supportive functions have been considered (Cohen \& Syme, 1985). Four negative functions were proposed by Rook and Pietromonaco (1987), including ineffective helping, excessive helping, negative regulation, and unpleasant interactions. Additional types of negativity may be operating in close relationships (see Jung, 1987; and Shinn et al., 1984). More conceptual work and attempts to operationalize these dimensions should be important goals for the future.

Our substantive analyses also leave many questions unanswered. We are far from understanding, for example, why supportive social interactions are so much more commonly reported than negative interactions, and why the ratio of supportive to negative interactions varies across relationships and between men and women. (See also Rook and Pietromonaco, 1987, pp. 20-23, on "negative biases.") Some preliminary insights into this issue were obtained in the disaggregated analysis, which showed that negative interactions are more likely to occur with relatives than with friends. This seems reasonable because kin relations are more permanent and obligatory than relationships with friends and cannot be terminated as easily in the presence of negative interactions. Nevertheless, there is still much to learn about why the ratio of supportive to negative interactions is much greater for some relationships than others. Interesting questions can be raised concerning structural characteristics associated with these ratios, as well as individual differences within and across types of relationships.

The simultaneous considerations of several different social relationships also documents that interactions with one's spouse are much more important for emotional well-being than interactions with relatives or friends. This is true for both men and women. Consistent with this results, Abbey et al. (1985) found that negative interactions with "the person closest to you" was by far the most important kind of social interaction for mood among university students. Indirect evidence for the predominant significance of negativity in the most intimate relationship can be found in the results of Ruehlman and Wolchik (1988). Focusing on personal goals and interpersonal support and hindrance, they observed that project hindrance by "the most important person" was of special significance in accounting for variation in both psychological distress and well-being. It is conceivable that much of the evidence suggesting that access to a secure and intimate relationship with a con- 
fidant promotes mental health (Brown \& Harris, 1978) could be elaborated usefully by introducing a consideration of negative interactions in such relationships.

It is significant that we found women to have more active relations than men with their kin. There is also a trend for women to be more emotionally responsive than men to negative kin interactions, which means that kin networks are somewhat more important for the emotional functioning of women than men. More work is needed to understand the basis of these sex difference (Belle, 1982; Kessler \& McLeod, 1984).

Another sex difference in these data is that, in terms of emotional functioning, women appear to benefit somewhat more than men from supportive interactions with all three types of relationships. This means that the greater exposure and emotional reactivity of women to negative interactions is in part negated by the stronger healing effects of supportive interactions. This conclusion is also in line with the results of Wethington and Kessler (1986), who suggested that the stress-buffering effect of social support may be somewhat stronger among women than men. Previous reviews of the social support literature have noted sex differences (House, Umberson, \& Landis, 1988), but no systematic research has been done to determine why they exist. There is reason to think that sex differences in interpersonal sensitivity might be involved, that women share the joys and sorrows of their loved ones more vividly than men, thus explaining why both supportive and negative social interactions affect the emotional well-being of women more strongly than men (Wethington, McLeod, \& Kessler, 1987). Explicit meaurement and testing of such ideas are required to take theorizing in this area beyond the current stage of speculation.

Finally, more research is needed to investigate the provocative finding of synergistic effects of supportive and negative interactions with relatives in predicting mood. Although the direct effects of negative versus supportive interactions are more strongly related to distress, these nonadditive effects indicate that social support nevertheless has an influence on emotional functioning, which is notably in the presence of negativity. One possible explanation is that negative interactions are potent stresses that are, to some degree, buffered by supportive interactions. If this is so, then it would be useful to know whether this happens through a process of appraisal in which the negative interaction is seen as less serious if the person with whom this interaction occurs is also someone who is supportive. We have indirect evidence to suggest that something of this sort occurs in the case of arguments, which generally are less distressing if they occur with a close loved one than with someone who is less well known (Bolger, DeLongis, \& Kessler, 1988), seemingly because a context of basic trust and caring creates an appraisal of the argument as less likely to pose a serious threat. More disaggregated analysis is now required to determine whether the same kinds of modifying effects occur for other sources of negative interactions. 
There is evidence that other types of appraisals and processes may be operating. Pagel et al. (1987) found "negative buffering" effects when assessing interactions at the network (aggregated) level; that is, upsetting interactions with network members appeared to be more distressing when they daparted from a general pattern of helpful network interactions, and that all of these effects influence depression (at least in part) via satisfaction with network support. Clearly, more refined disaggregated analyses and analyses of interaction processes are required to decipher these effects. Such analyses are extremely important because they document in a very direct way that an understanding of social support effects depends centrally on the amount of negativity in relationships with those who are providing the support. This demonstrates clearly that future research on social support needs to consider both supportive and negative aspects of social relationships at the same time.

\section{REFERENCES}

Abbey, A., Abramis, D. J., \& Caplan, R. D. (1985). Effects of different sources of social support and social conflict on emotional well-being. Basic and Applied Social Psychology, $6,111-129$.

Barrera, M. (1981). Social support in the adjustment of pregnant adolescents: Assessment issues. In B. H. Gottlieb (Ed.), Social networks and social support (pp. 69-96). Beverly Hills: Sage.

Belle, D. (1982). Social ties and social support. In D. Belle (Ed.), Lives in stress: Women and depression (pp. 133-144). Beverly Hills: Sage.

Bolger, N., DeLongis, A., \& Kessler, R. C. (1988). The structure of daily stress. Unpublished manuscript, Institute for Social Research, The University of Michigan.

Brown, G. W., \& Harris, T. (1978). Social origins of depression: $A$ study of psychiatric disorder in women. New York: Free Press.

Bradburn, N. M., \& Caplovitz, D. (1965). Reports on happiness. Chicago: Aldine.

Cohen, S., \& Hoberman, H. M. (1983). Positive events and social supports as buffers of life change stress. Journal of Applied Social Psychology, 13, 99-125.

Cohen, S., \& Syme, L. S. (Eds.). (1985). Social support and health. New York: Academic Press.

Coyne, J. C., \& DeLongis, A. (1986). Going beyond social support: The role of social relationships in adaptation. Journal of Consulting and Clinical Psycholgy, 54, 454-460.

Denoff, M. S. (1982). The differentiation of supportive functions among network members: An empirical inquiry. Journal of Social Service Research, 5, 45-59.

Derogatis, L. R. (1977). SCL-90: Administration, scoring, and procedures manual for the revised version. Baltimore, MD: Johns Hopkins University.

Diener, E. (1984). Subjective well-being. Psychological Bulletin, 95, 542-575.

Dunkel-Schetter, C. (1984). Social support and cancer: Findings based on patient interviews and their implications. Journal of Social Issues, 40(4) 77-98.

Eckenrode, J., \& Gore, S. (1981). Stressful events and social supports: The significance of context. In B. H. Gottlieb (Ed.), Social networks and social support (pp. 43-68). Beverly Hills: Sage.

Fiore, J., Becker, J., \& Coppel, D. B. (1983). Social network interactions: A buffer or a stress? American Journal of Community Psychology, 11, 423-439.

Gottlieb, B. H. (1985). Social networks and social support: An overview of research, practice, and policy implications. Health Education Quarterly, 12, 5-22.

Henderson, S., Duncan-Jones, P., McAuley, H., \& Ritchie, K. (1978). The patient's primary group. British Journal of Psychiatry, 132, 74-86. 
Henderson, S., Byrne, D., Duncan-Jones, P., Scott, R., \& Adcock, S. (1980). Social relationships, adversity, and neurosis: A study of associations in a general population sample. British Journal of Psychiatry, 136, 574-583.

Henderson, S., Byrne, D., Duncan-Jones, P., Adcock, S., Scott, R., \& Steele, G. (1978). Social bonds in the epidemiology of neurosis: A preliminary communication. British Journal of Psychiatry, 132, 463-466.

Hirsch, B. (1981). Social networks and the coping process. In B. H. Gottlieb (Ed.), Social networks and social support (pp. 149-170). Beverly Hills: Sage.

House, J. S., Landis, K. R., \& Umberson, D. (1988). Social relationships and health: A matter of life and death. Science, $241,540-545$.

House, J. S., Umberson, D., \& Landis, K. R. (1988). Structures and processes of social support. Annual Review of Sociology, 14, 293-318.

Jung, J. (1987). Toward a social psychology of social support. Basic and Applied Social Psychology, 8, 57-83.

Kessler, R. C. (1983). Methodological issues in stress research: Design and analysis. In H. B. Kaplan (Ed.), Psychosocial stress: Recent developments in theory and method (pp. 267-342). New York: Academic Press.

Kessler, R. C., \& McLeod, J. D. (1984). Sex differences in vulnerability to undesirable life events. American Sociological Review, 49, 620-631.

Kessler, R. C., McLeod, J. D., \& Wethington, E. (1985). The costs of caring: A perspective on the relationship between sex and psychological distress. In I. G. Sarason \& B. R. Sarason (Eds.), Social support: Theory, research, and applications (pp. 491-507). The Hague: Martinus Nijoff.

Kobasa, S. C. O., \& Puccetti, M. C. (1983). Personality and social resources in resistance. Journal of Personality and Social Psychology, 45, 839-850.

LaRocco, J. M., House, J. S., \& French, J. R. P. (1980). Social support, occupational stress and health. Journal of Health and Social Behavior, 21, 202-218.

Lehmann, S., Shinn, M., Allen, J., \& Simko, P. (1983). Measuring social supports. Paper presented at a meeting of the American Psychological Association, Anaheim, CA.

Mattlin, J., Wethington, E., Kessler, R. C. (in press). Situational determinants of coping and coping effectiveness in a general population sample. Journal of Health and Social Behavior.

O'Brien, K., Wortman, C. B., \& Joseph, J. G. (1986). Effects of social support on a cohort at risk. Paper presented at a meeting of the American Psychological Association, Washington, DC.

Orden, S. R., \& Bradburn, N. M. (1968). Dimensions of marriage happiness. American Journal of Sociology, 73, 715-731.

Pagel, M. D., Erdly, W. W., \& Becker, J. (1987). Social networks: We get by with (and in spite of) a little help from our friends. Journal of Personality and Social Psychology, 53, 793-804.

Pearlin, L. I., Lieberman, M. A., Menaghan, E. G., \& Mullan, J. F. (1981). The stress process. Journal of Health and Social Behavior, 22, 337-356.

Pittman, J. F., \& Lloyd, S. A. (1988). Quality of family life, social support, and stress. Journal of Marriage and the Family, 50, 53-67.

Rook, K. S. (1984). The negative side of social interaction: Impact on psychological well-being. Journal of Personality and Social Psychology, 46, 1097-1108.

Rook, K. S., \& Pietromonaco, P. (1987). Close relationships: Ties that heal or ties that bind? Advances in Personal Relationships, 1, 1-35.

Rosario, M., Shinn, M., Morch, H., \& Huckabee, C. B. (1988). Gender differences in coping and social supports: Testing socialization and role constraint theories. Journal of Community Psychology, I6, 55-69.

Ruehlman, L. S., \& Wolchik, S. A. (1988). Personal goals and interpersonal support and hindrance as factors in psychological distress and well-being. Journal of Personality and Social Psychology, 55, 293-301.

Sandler, I. N., \& Barrera, M., Jr. (1984). Toward a multimethod approach to assessing the effects of social support. American Journal of Community Psychology, 12, 37-52. 
Shinn, M., Lehmann, S., \& Wong, N. W. (1984). Social interaction and social support. Journal of Social Issues, 40(4), 55-76.

Stephens, M. A. P., Kinney, J. M., Ritchie, S. W., \& Norris, V. K. (1987). Social networks as assests and liabilities in recovery from stroke by geriatric patients. Psychology and Aging, 2, 125-129.

Turner, R. J., Frankel, G., \& Levin, D. M. (1983). Social support: Conceptualization, measurement, and implications for mental health. In J. R. Greenley \& R. G. Simmons (Eds.), Research in Community and Mental Health (pp. 67-111). Greenwich: JAI Press.

Veroff, J., Douvan, E., \& Kulka, R. (1981). The inner American: A self-portrait from 1957-1976. New York: Basic Books.

Weiss, R. S. (1974). The provisions of social relationships. In Z. Rubin (Ed.), Doing Unto Others (pp. 17-26). Englewood Cliffs, NJ: Prentice-Hall.

Wethington, E., \& Kessler, R. C. (1986). Perceived support, received support, and ajustment to stressful live events. Journal of Health and Social Behavior, 27, 78-89.

Wethington, E., McLeod, J. D., \& Kessler, R. C. (1987). The importance of life events for expaining sex differences in psychological distress. In R. C. Barnett, G. K. Baruch, \& L. B. Biener (Eds.), Gender and stress ((pp. 144-156). New York: Basic Books

Wills, T. A., Weiss, R. L., \& Patterson, G. R. (1974). A behavioral analysis of the determinants of marital satisfaction. Journal of Consulting and Clinical Psychology, 42, 802-811.

Wong, N. W. (1985/1986). Effects of individual sources of support on well-being in employed parents (Doctoral dissertation, University of Michigan, 1985). Dissertation Abstracts International, 46, 2504B.

Wood, V., \& Robertson, J. (1978). Friendship and kinship interaction: Differential effect on the morale of the elderly. Journal of Marriage and the Family, 40, 367-373.

Wortman, C. B., \& Dunkel-Schetter, C. (1987). Conceptual and methodological issues in the study of social support. In A. Baum \& J. E. Singer (Eds.), Handbook of psychology and health: Vol. 5. Stress (pp. 63-108). Hillsdale, NJ: Erlbaum.

Wortman, C. B., \& Lehmann, D. R. (1985). Reactions to victims of life crisis: Support attempts that fail. In I. G. Sarason \& B. R. Sarason (Eds.), Social support: Theory, Research, and applications (pp. 463-489). The Hague: Martinus Nijoff. 